\title{
Transforming Our Thinking about Transitional Forms
}

\author{
Louise S. Mead
}

Published online: 16 April 2009

(C) Springer Science + Business Media, LLC 2009

\begin{abstract}
A common misconception of evolutionary biology is that it involves a search for "missing links" in the history of life. Relying on this misconception, antievolutionists present the supposed absence of transitional forms from the fossil record as evidence against evolution. Students of biology need to understand that evolution is a branching process, paleontologists do not expect to find "missing links," and evolutionary research uses independent lines of evidence to test hypotheses and make conclusions about the history of life. Teachers can facilitate such learning by incorporating cladistics and tree-thinking into the curriculum and by using evograms to focus on important evolutionary transitions.
\end{abstract}

Keywords Macroevolution · Transitional features · Creationism $\cdot$ Tree-thinking $\cdot$ Cladistics $\cdot$ Evograms

The inadequacy of the fossil record to document fully all major evolutionary transitions continues to provide a basis for creationists to undermine evolution education. This was apparent in a recent proposed amendment to the Texas Essential Knowledge and Skills document that asked students to "analyze and evaluate the sufficiency and insufficiency of common ancestry to explain the sudden appearance... of groups in the fossil record" (Texas State Board of Education Meeting. 22 January, 2009). Even when confronted with an exemplary extensive fossil record showing step-by-step transitions, as is now available for the evolutionary transition from land mammals to whales, creationists commonly

L. S. Mead $(\bowtie)$

National Center for Science Education,

P.O. Box 9477, Berkeley, CA 94709-0477, USA

e-mail: mead@ncseweb.org respond that such an array of fossils corresponds to species that are not along a direct line of descent and therefore not evidence of macroevolutionary change.

A reluctance adequately to address macroevolution also characterizes textbooks, as noted by Padian (2008): Even the best high school biology textbooks omit a comprehensive presentation of macroevolution. Clearly, the problem with "missing links" as evidence against evolution is "insoluble when dealing with anyone who does not want to accept that there could be transitional forms" (Padian and Angielczyk 2007:204). High school teachers can, however, redirect students toward a better understanding of macroevolution as well as current paleontological practice by (1) focusing on transitional features rather than the "missing link" or transitional forms, (2) incorporating tree-thinking and introducing cladistics into the life science and biology curriculum, and (3) presenting evograms to depict major transitions in evolution.

\section{The Missing Link}

The concept of a "missing link" is an "archaic expression" (Padian and Angielczyk 2007) tracing back to the Great Chain of Being, a view of the physical and metaphysical world as an unbroken chain. It was later temporalized by the evolutionary thought of the eighteenth and nineteenth century to the idea of evolution as a progressive climb up a ladder (Ruse 1997). These views of evolution create the false expectation that there should be fossil evidence showing "a complete chain of life from simple to complex" (Vardiman 2003:328). Creationists rely on such views to support their arguments against macroevolution, in particular by pointing out the "conspicuous" absence of "large numbers of intermediate fossil organisms" (Changing lives 2003), using what 
is still unknown to question whether evolution has occurred. I will deal with the misconception of evolution as a ladderlike progression shortly, but should the fossil record be expected to reveal all species that have ever lived? Clearly not. Knowledge of the fossil record will never be comprehensive (Darwin 1859; Padian and Angielczyk 2007; Prothero 2007). First, there is too much of the Earth to explore, and paleontologists have to be content with samples. Second, given our knowledge of geology, we understand that not all organisms will be fossilized and that there will be systematic biases in what organisms are fossilized (Kidwell and Holland 2002). Therefore, any statements rest on a fallible, if informed, assessment of the necessarily incomplete evidence.

Even if one does not expect that the whole Great Chain of Being should be found in the fossil record, there is yet another outmoded view of evolution driving creationist antievolution propaganda. Expectations of "intermediate" forms reflect neither Darwin's original thoughts nor current thinking and practices in evolutionary biology and paleontology. Darwin (1859) was very clear on this. The ancestor of two living forms is unlikely to be found alive because it would have been outcompeted in most cases by newly adapting forms, and an extinct ancestor of two living forms would not be expected to look intermediate between them. Today, evolutionary biologists and paleontologists do not focus on finding "intermediates" but rather on reconstructing evolutionary relationships and history using shared derived characters, or synapomorphies. Willi Hennig revolutionized systematics in the 1960s with the introduction of cladistics, which ushered in a new method of phylogenetic analysis and a new approach to systematics. Instead of relying on a Linnaean system of classification, cladistics placed the focus on evolutionary history, specifically identifying features as ancestral (general) or derived (evolved after the lineage split from the ancestor). If a shared derived character, or synapomorphy, is found in two or more related organisms, it is inferred to have been present in their common ancestor, irrespective of whether or not there is a fossil record for that ancestor (Hennig 1966). Rather than trying to find the actual fossil corresponding to the "missing link" between lobe-fins and tetrapods, paleontologists instead look for fossils with characters or features important for an adaptive transition from life in an aquatic environment to life on land and that are shared as the result of common ancestry.

\section{Shoots vs. Ladders}

Thinking of evolution as a progression from simple to complex, or ladder-like, furthers the idea that evolution is lineal and that it should be possible to reconstruct a direct line of ancestors. However, the evolution of life, instead of resembling a ladder, is more similar to a branching bush. Darwin's (1859) contribution to phylogenetic analysis indeed was to introduce the concept of a branching tree of life, with organisms related through common ancestry (Fig. 1). Each branch on the tree represents a distinct lineage; multiple branches can extend from a common point, joined by a set of characters present in the common ancestor; lineages can also acquire characters that are not shared in a common ancestor. Finally, as a result of extinction, not all lineages persist into the future, as can clearly be seen in Fig. 1. Tree-thinking shifts the focus from looking for fossils of lineal (direct) ancestors to looking for synapomorphies that link collateral (side-branch) ancestors. Your grandmother is a lineal ancestor, your great-aunt a collateral ancestor (Fig. 2), but their lives and times were probably not that different (Padian and Angielczyk 2007),
Fig. 1 The diagram of divergence of taxa presented by Charles Darwin in On the origin of species (1859)

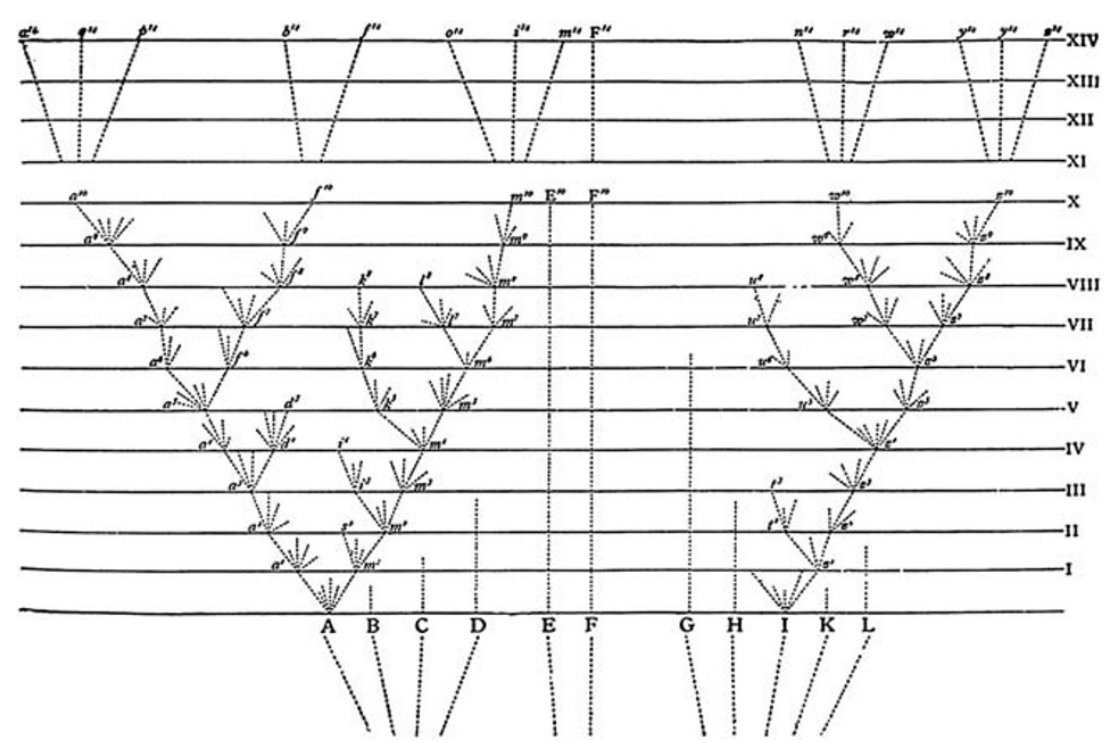


Fig. 2 Sample family tree for an individual (you) showing your collateral (indicated by dashed lines) and direct or lineal (indicated by solid lines) ancestors

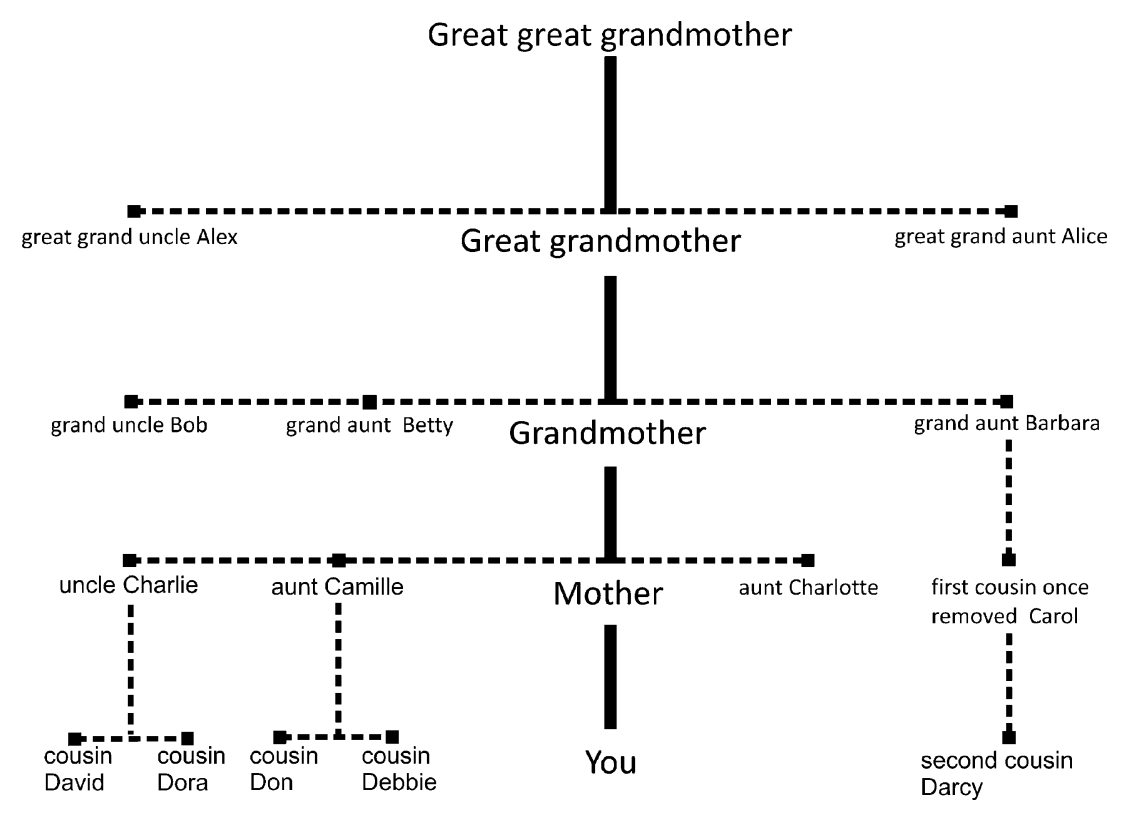

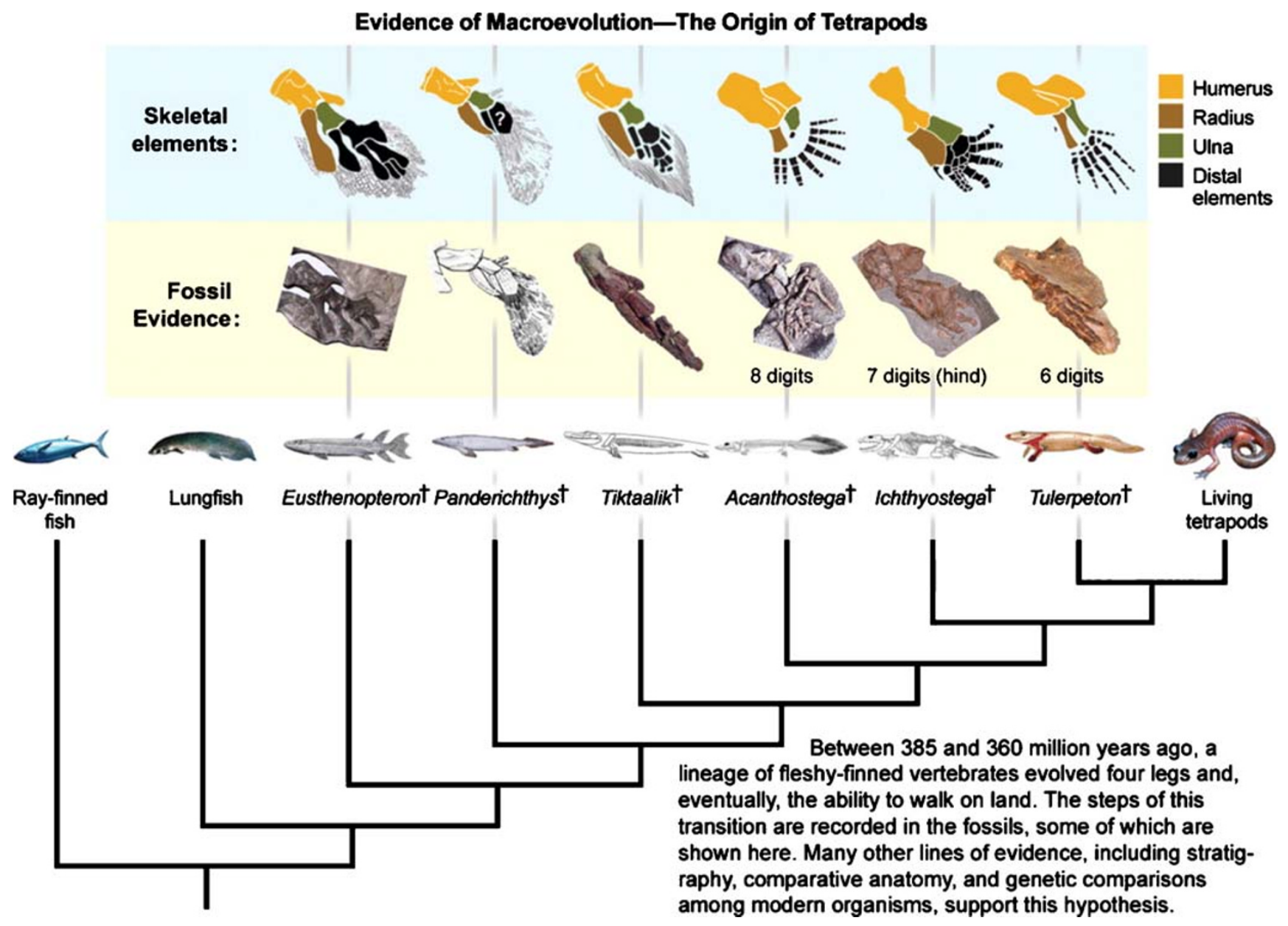

Fig. 3 "Evogram" by Brian Swartz and Josh Frankel of UCMP (Padian 2008) printed with permission of Oxford University Press and the Society for Integrative and Comparative Biology 
which means that information about one provides information about the other. Paleontologists do not expect to find the direct lineal ancestor of an extant species (Padian and Angielczyk 2007), nor do they expect to recognize a direct ancestor as "the ancestor" even if they did find it. However, by understanding the lives and times of the species in its family tree, they can understand what its ancestor would have been like.

\section{Figure on Adaptive Change}

David Attenborough recently declared in a program about Darwin that "you'd have to be extraordinarily blinkered if you didn't stub your toe against the theory of evolution very early on in your life," particularly if as a child you collected fossils (Charles Darwin and the tree of life 2009). The data to substantiate many of the major transitions in evolution have been amassed. Lines of evidence include cladograms from independent datasets (i.e., fossils, morphology, and molecules), stratigraphy and radiometric dating to establish events in time, and paleoecology to interpret ancient environments. Embryology, behavior, histology, geochemistry, functional morphology, physiology, and biochemistry all add to the array of independent lines of evidence used to test evolutionary hypotheses.

Padian (2008) suggests depicting these various lines of evidence, particularly the ones that are important in major evolutionary transitions, in a single diagram, called an "evogram" (Fig. 3), to help students to understand that evolutionary research is conducted in an integrative way and in a way that relies on testing independent lines of evidence against each other to demonstrate concordance. Evograms have a cladogram as the backbone of the diagram, generated using an entirely separate base of information. Because a cladogram is basic to understanding evolutionary relationships, other types of noncladogram evolutionary diagrams will only confuse students (Catley and Novick 2008). In Fig. 3, fossil evidence of limb structure is depicted in one row. Structures of the fossils, showing corresponding bones in corresponding colors, are interpreted in the next row. Important clade names and important synapomorphies can also be added to the nodes of the cladogram (Padian 2008). Evograms integrate the various independent lines of evidence, providing a more united picture of evolution.

The challenge is that teachers are generally neither trained nor equipped to teach this way. Indeed, treethinking has only recently trickled down to high school biology (Goldsmith 2003; Catley 2006; Baum and Offner 2008). Most high school and many college introductory biology texts are woefully lacking in their presentation of comprehensive figures integrating phylogenetic analyses with hypotheses about evolutionary process. In fact, it appears that many of the diagrams may actually be misleading (Catley and Novick 2008). In a recent analysis of evolutionary diagrams in biology textbooks, Catley and Novick (2008) found that even though $72 \%$ of the diagrams in their survey of 31 textbooks were cladograms, there were striking differences across grade levels. Middle school texts had the fewest cladograms, with almost twice as many noncladograms. High school texts included more cladograms, but the ratio of cladograms to noncladograms was approximately equal. Such high proportions of noncladograms are disturbing if these support misconceptions about evolutionary processes (Catley and Novick 2008).

I urge teachers to embrace cladistics and tree-thinking as a way of examining the natural world and to encourage students to make such thinking a habit. For a first step, the following websites offer basic exercises on cladistics and tree-thinking: Evolution and the Nature of Science Institutes (http://www. indiana.edu/ ensiweb); Understanding Evolution (http:// evolution.berkeley.edu); What did T. rex taste like? (http:// www.ucmp.berkeley.edu/education/explorations/tours/Trex). Also recommended are ways of teaching about evolution consistent with modern practice in systematics: using "ancestral" and "derived" instead of "primitive" and "advanced" when referring to organisms and characters, which promotes thinking about evolution as a tree rather than a ladder (and also follows the good example of Darwin, who admonished himself, "Never use the words higher or lower"); including exercises that define clades by synapomorphies and map such characters onto phylogenies (see Staub et al. 2006 and ENSI: Making Cladograms); and clarifying that a cladogram or phylogenetic tree is a hypothesis, given the data, and that a node on a cladogram is a hypothetical ancestor, not an actual ancestor for which we should expect to find a fossil representative. To attain scientific literacy, students need to learn that evolution is a branching process, that paleontologists are not searching for missing links but for transitional features, and that evolutionary research is conducted in a way that enables scientists to use independent lines of evidence to converge on robust conclusions about the history of life. Teachers need to learn these lessons in order to be able to impart them!

\section{References}

Baum D, Offner S. Phylogenies and tree-thinking. Am Biol Teach. 2008; 70(4):222-9. doi:10.1662/0002-7685(2008)70[222:PT]2.0.CO;2.

Catley KM. Darwin's missing link - a novel paradigm for evolution education. Sci Educ. 2006;90:767-83. doi:10.1002/sce.20152.

Catley KM, Novick L. Seeing the wood for the trees: an analysis of evolutionary diagrams in biology textbooks. Bioscience. 2008;58:969-87. doi:10.1641/B581011.

Changing lives (2003) http://www.changinglivesonline.org/evolution. html. 
Charles Darwin and the tree of life. Broadcast on BBC One, Sunday 1 February 2009. http://www.bbc.co.uk/programmes/b00hd5mf.

Darwin C. On the origin of species by means of natural selection. London: Murray; 1859.

Goldsmith DW. Presenting cladistic thinking to biology majors and general science students. Am Biol Teach. 2003;65(9):679-92.

Hennig W. Phylogenetic systematics (trans. D.D. Davis and R. Zangerl). Urbana: University of Illinois Press; 1966.

Kidwell SM, Holland SM. The quality of the fossil record: implications for evolutionary analyses. Annu Rev Ecol Syst. 2002;33:561-88. doi:10.1146/annurev.ecolsys.33.030602.152151.

Padian K. Trickle-down evolution: an approach to getting major evolutionary adaptive changes into textbooks and curricula. Integr Comp Biol. 2008;48:175-88. doi:10.1093/icb/icn023.

Padian K, Angielczyk KD. "Transitional" forms versus transitional features. In: Petto AJ, Godfrey LR, editors. Scientists confront intelligent design and creationism. New York: Norton; 2007. p. $197-230$.

Prothero DR. Evolution: what the fossils say and why it matters. New York: Columbia University Press; 2007.

Ruse M. Monad to man: the concept of progress evolutionary biology. Cambridge: Harvard University Press; 1997.

Staub NL, Pauw PG, Pauw D. Seeing the forest through the trees: helping students appreciate life's diversity by building the tree of life. Am Biol Teach. 2006;68(3):49-51. doi:10.1662/0002-7685 (2006)68[149:STFTTT]2.0.CO;2.

Texas State Board of Education Meeting. 22 January 2009. Amendments of Don McLeroy. http://www.texscience.org/pdf/mcleroy-biologyamendments.pdf.

Vardiman L. In Ashton JF, editor. In six days: why 50 scientists choose to believe in creationism. Green Forest, AR: Master Books; 2003. p. $327-328$. 